\title{
O valor econômico da savana metalófita da Floresta Nacional de Carajás, estado do Pará: uma contribuição teórica e metodológica
}

\author{
Antônio Cordeiro de Santana* \\ Rafael Paiva Salomão** \\ Ádamo Lima de Santana**** \\ Alexandre F. Castilho****** \\ Sérgio Castro Gomes
}

\begin{abstract}
Resumo
O objetivo deste trabalho é estimar o valor econômico da vegetação de canga da Flona de Carajás, que inclui espécies raras e endêmicas. Utilizou-se uma abordagem econômica e ecológica na escolha das variáveis explanatórias do modelo integrado de avaliação contingente (MIAC), especificado pelas equações de disposição a pagar (DAP), pela preservação de disposição a receber (DAR) e pela indenização da canga. Os valores médios da DAP e da DAR foram, respectivamente, de $\mathrm{R} \$ 4.073,84 /$ ha e $\mathrm{R} \$ 4.415,56 / \mathrm{ha}$. A diferença entre esses valores médios foi de apenas $8,39 \%$ em função do esclarecimento feito aos entrevistados sobre as características e as potencialidades econômicas e ecológicas da canga. Os valores da DAP e da DAR foram compostos pelas dimensões econômica de $52,1 \%$ e de $59,5 \%$, sociodemográfica de $11,7 \%$ e $10,2 \%$, de serviços ecossistêmicos de $20,05 \%$ e $16,8 \%$ e a tácita de $15,7 \%$ e $13,6 \%$.
\end{abstract}

Palavras-chave: Amazônia. Ativo natural. Recursos naturais. Serviços ecossistêmicos.

* Engenheiro-Agrônomo, Doutor do Instituto Socioambiental e dos Recursos Hídricos, da Universidade Federal Rural da Amazônia. E-mail: acsufra@gmail.com

** Engenheiro-Florestal, Doutor do Museu Paraense Emílio Goeldi/MCTI. E-mail: salomão@museu-goeldi.br

*** Engenheiro da Computação, Doutor da Faculdade de Engenharia da Computação, da Universidade Federal do Pará. E-mail: adamo@ufpa.br

******* Engenheiro-Agrônomo, Pesquisador e Mestre da Vale do Rio Doce. E-mail: alexandre.castilho@vale.br

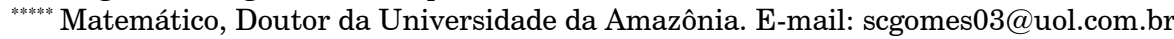

http://dx.doi.org/10.5335/rtee.v23i48.7358

Submissão: 15/10/2016. Aceite: 05/12/2016. 


\section{Introdução}

A Floresta Nacional de Carajás (Flona de Carajás), no estado do Pará, possui grande estoque de ferro, cujo direito de exploração pertence à empresa mineradora Vale do Rio Doce (Vale). A área com a vegetação de savana metalófita, também denominada de canga, foi o ativo natural valorado. A canga, onde a rocha com o minério de ferro aflora, é um ecossistema ímpar no bioma Amazônia, representando entre 4\% e 5\% dos 411.949 ha da Flona de Carajás (CAMPOS; CASTILHO, 2012). A vegetação da canga é composta de gramíneas, espécies arbustivas e rupestres, capão de mata (floresta), espécies de áreas inundáveis, jaborandi (Pilocarpus microphyllus Stapf ex Wardleworth), buriti (Mauritia flexuosa Mart.) e espécies raras e/ou endêmicas, como a Flor de Carajás (Ipomoea cavalcantei D. Austin).

Nesta área, coletam-se ramos do jaborandi para fins comerciais e exercita-se o turismo ecológico de visitantes com interesse em cotejar um ambiente que contrasta com a floresta amazônica, situado no "coração" da Amazônia. Ocorre que parte desse ativo natural deve ser suprimido a fim de viabilizar a extração do minério de ferro. Para isto, uma parcela da canga é preservada e a outra, cuja vegetação é suprimida, a Vale indeniza. O valor é repassado ao Instituto Chico Mendes de Conservação da Biodiversidade (ICMBio) e o Instituto Brasileiro do Meio Ambiente e dos Recursos Naturais Renováveis (Ibama), órgãos do governo federal, responsáveis pela regulação ambiental que autoriza a atividade de mineração na área.

Quando a área a ser minerada é coberta por florestas, aplica-se a metodologia de análise benefício-custo, definida no Termo de Referência do Instituto Chico Mendes de Conservação da Biodiversidade (ICMBio, 2012), dado que se trata de produtos madeireiros e não madeireiros que são comercializados no mercado. $\mathrm{Na}$ canga, os recursos naturais, em geral, não têm valor de mercado, e algumas espécies se enquadram na categoria dos recursos raros e/ou endêmicos que devem ser preservados pelo valor de opção e/ou valor de existência. Assim, qual o Valor Econômico Total (VET) a ser imputado à vegetação desse ativo natural?

O desafio deste trabalho foi propor um Método Integrado de Avaliação Contingente (MIAC) para estimar o VET (valor de uso direto e indireto, valor de opção e valor de existência) da vegetação de canga da Flona de Carajás, levando em conta variáveis descritoras das dimensões econômica, sociodemográfica, ambiental e ecológica. Optou-se pelo método da avaliação contingente integrada em função de sua adequação a essa abordagem sistêmica para estimar o valor de ativos naturais com alguns recursos que ainda não são transacionados nos mercados. 
A integração dos princípios econômicos e ecológicos na metodologia de valoração dos ecossistemas florestais é fundamental neste caso, porque a canga gera produtos e serviços. Nas áreas de capão de mata, a madeira tem preço de mercado, assim como o jaborandi e o fruto do buriti. Contudo, os campos arbustivos e seus produtos e serviços ainda não têm preço de mercado. $\mathrm{O}$ atual uso econômico e ecológico dessa área é feito pelo turismo ecológico e de contemplação, cuja taxa ainda está se adequando ao custo de oportunidade da visitação deste cenário exótico. Portanto, se adotada a análise benefício-custo, ou qualquer outro método de análise parcial, a soma dos valores das áreas, cujos produtos e serviços têm preço de mercado, apresenta-se, tendencialmente inferior ao VET do ativo ambiental, gerado com a aplicação do MIAC.

Assim, qual o valor econômico total da vegetação de canga da Flona de Carajás a ser indenizada pela Vale? Para responder essa questão, aplicou-se o MIAC com a finalidade de estimar o valor econômico total da canga a partir da preferência declarada pela população local quanto à Disposição a Receber (DAR) uma indenização pela vegetação da área de canga e a viabilizar a extração do minério de ferro, e à Disposição a Pagar (DAP) pela preservação da canga, um ativo que também faz parte da regulação dos recursos naturais da Amazônia por parte do ICMBio.

O MIAC integrou tais decisões em um sistema de equações para a análise simultânea e, assim, contemplou os fundamentos teóricos das equações DAP e DAR para a valoração da vegetação da canga. O objeto do trabalho foi aplicar o MIAC para estimar o VET da vegetação de canga com fins de indenização, considerando a existência de recursos raros, endêmicos, e sua importância ecológica e socioeconômica para a população amazônica.

\section{Referencial teórico}

A atribuição de valor aos recursos naturais, não obstante sua importância em apoio à formulação e ao ajuste de políticas públicas para a regulação do uso dos recursos naturais, é uma tarefa complexa, porque uma parte dos ativos naturais tem valor definido no mercado e outra parte não tem valor de uso ou valor de troca, dado que ainda não foi inserida nas transações comerciais.

Os produtos e os serviços produzidos por ativos naturais englobam as complexas relações entre os seres vivos e os abióticos, que determinam a capacidade da natureza de proporcionar qualidade de vida e comodidade para os seres humanos (COSTANZA et al., 1997). Como definido em Costanza e Daly (1992) e Costanza et al. (1997), os serviços ecossistêmicos podem ser enquadrados em quatro categorias:

Teoria e Evidência Econômica - Ano 23, n. 48, p. 9-38, jan./jun. 2017 
(i) serviços de provisão, que abrangem produtos como alimentos e fibras, madeira, recursos genéticos, produtos bioquímicos, medicinais, farmacêuticos, ornamentais e água; (ii) serviços de regulação ambiental, que contemplam o controle do clima, polinização, doenças e pragas, purificação da água e do ar e proteção contra desastres; (iii) serviços culturais, que envolvem valores culturais, religiosos e espirituais, conhecimento, recreação, valores educacionais e paisagísticos; e (iv) serviços de suporte, que definem a produção de outros serviços, como a formação e retenção do solo, a fotossíntese, a ciclagem de nutrientes, a atividade biológica do solo, a ciclagem da água e a manutenção da dinâmica do habitat. Portanto, sem esses serviços e produtos não há melhoria na qualidade de vida. Para assegurar o fornecimento contínuo deles à sociedade é necessário atribuir-lhes um valor econômico.

A especificidade dos ativos naturais amplia a complexidade para se chegar a uma aproximação do VET, sobretudo, quando inclui espécies raras e/ou endêmicas, cujo valor de uso e/ou de não uso ainda é uma incógnita. Além disso, depara-se com o baixo grau de conhecimento da sociedade sobre a contribuição direta e indireta desses ativos para assegurar o crescimento econômico e o bem-estar da humanidade. Portanto, conhecer o valor dos ativos naturais é fundamental para a determinação do valor da disposição a pagar ou a receber compensação em montante, equivalente à variação do estoque destes ativos.

Nesse contexto, ao incorporar o valor de uso e o valor de não uso dos ativos naturais, o VET tornou-se mais difundido e aplicado a diversas categorias de ecossistemas, sobretudo por contemplar situações de incerteza e intertemporalidade. Em função disso, Randall e Stoll (1980) apresentaram uma estrutura analítica para o VET, contemplando o valor de uso (VU) e o valor de não uso (VNU) dos ativos naturais relacionados aos princípios da teoria microeconômica.

Para tornar o conceito de VET mais claro e operacional, Bishop e Romano (1982) separaram o VU dos ativos ambientais em valor de uso direto (VUD) e valor de uso indireto (VUI):

- O VUD trata do consumo do ativo natural (madeira extraída da floresta, produtos oriundos de caça e pesca, coleta de frutos, água potável e para irrigação, observação de paisagens, pássaros e outros). A ideia é que, ao utilizar os sentidos (visão, audição, tato, paladar e olfato) em uma experiência com recurso natural, está-se fazendo uso direto do recurso. Na canga, a prática do turismo ecológico e da coleta do jaborandi são formas de uso direto do recurso natural.

- O VUI está associado à obtenção de satisfação por meio de leitura, reportagens e vídeos sobre o uso de tais recursos, pelo fato de que realizam funções 
ecológicas vitais para a manutenção da biodiversidade dos ecossistemas, das bacias hidrográficas, da regulação do clima da ciclagem de nutrientes e outros, que influenciam diretamente no bem-estar das pessoas. A canga representa esse valor pelo conhecimento divulgado em notícias sobre espécies raras e endêmicas a partir de estudos realizados pela Vale e de reportagens divulgadas na mídia.

$\mathrm{O}$ VNU surge do reconhecimento de que o recurso natural existe, sem a necessidade do uso direto ou indireto. A valoração do VNU tem recebido diversos termos: valor de existência e de opção, por Randall e Stoll (1980); valor intrínseco, por Fisher, Krutilla, e Ciccheth (1972) e Fisher e Hanemann (1987); e valor de preservação, por Sutherland e Walsh (1985), em função de uma gama de razões, incluindo o legado desse direito deixado para usufruto de gerações futuras, dado o senso de gestão ou responsabilidade para preservar certas características dos recursos naturais. No caso da canga, a Flor de Carajás, a existência de cavernas e de lagos tornam o ativo enquadrado nessa categoria de valor.

Portanto, em situação de incerteza sobre o futuro, um indivíduo com aversão ao risco e diante da possibilidade de fazer uma melhor escolha de uso para o recurso natural, pode agir de forma racional e optar pelo uso do recurso no futuro. Neste caso, dois outros ingredientes são considerados para representar a componente VNU no conceito de VET: o valor de opção (VO) que, conforme Bishop (1982), se refere ao prêmio de risco associado à incerteza sobre o valor que o indivíduo está disposto a pagar pela preservação do recurso natural sem depender do tempo; e o valor de quase opção (VQO), apresentado por Arrow e Fisher (1974) e desenvolvido por Fisher e Hanemann (1987) e Hanemann (1991), que está associado ao aspecto intertemporal da incerteza ao assumir que uma dada decisão pode ter, pelo menos em parte, um efeito irreversível. Como o ecossistema de canga é diferenciado por abrigar espécies raras e/ou endêmicas como a Flor de Carajás, a sociedade pode decidir preservar a área para as gerações futuras.

O valor de existência (VE) do ativo natural, segundo Krutilla (1967), Randall e Stoll (1980), Pearce (1990), Loomis e White (1996), Amirnejad et al. (2006) e Richardes e Loomis (2009), é atribuído a certos recursos naturais pelo fato de sua existência, independente de quaisquer formas de utilização. O fundamento está relacionado com os agentes, pela simpatia que inspiram certas espécies de animais ou, de forma mais geral, pelo reconhecimento do direito à existência dos não humanos. Assim, as pessoas tendem a avaliar um ativo natural, mesmo sem 0 consumo direto ou indireto, pelo simples fato de serem altruístas para com amigos, familiares e futuras gerações (BISHOP; ROMANO, 1998). Neste aspecto, a canga 
apresenta a Flor de Carajás como espécie endêmica, fato que desperta o interesse da sociedade para preservá-la nas áreas de canga da Flona de Carajás.

A inclusão dessa componente no conceito de VET o tornou sujeito a críticas do ponto de vista econômico, uma vez que o VE não estaria ligado a nenhuma forma de utilidade, porque independe da utilização. Por outro lado, pode-se considerar o valor de opção no sentido amplo, como o reagrupamento do conjunto de elementos que não está ligado ao consumo direto ou indireto do ativo, mas à sua existência. Contudo, as formas de reagrupamento tendem a se tornar arbitrárias, sendo mais operacional definir o VET como a soma do valor de uso, do valor de opção e do valor de existência, como fizeram Pearce (1990), Loomis et al. (2000), Torras (2000), Adams et al. (2008) e Santana et al. (2015).

VET = Valor de Uso (VU) + Valor de Opção (VO) + Valor de Existência (VE)

O VET está ancorado no conceito de excedente econômico, aplicado por Randall e Stoll (1980). Portanto, o valor econômico total é definido pela área abaixo da curva de demanda, delimitada pela quantidade consumida do bem ou serviço no mercado (CARSON et al., 1998; COSTANZA et al., 1997; LIU et al., 2010; SANTANA et al., 2015). Para o caso dos produtos que têm preços de mercado, a abordagem da demanda é a mais adequada para medir o VET de um ativo ambiental (SANTANA et al., 2015).

\subsection{Abordagem da avaliação contingente}

A valoração dos recursos naturais restringia-se aos métodos do valor instrumental, que incorporava apenas os aspectos econômicos do capital natural. Entretanto, os ativos naturais são multifuncionais, sendo ou não transacionados nos mercados. Portanto, qualquer análise que leva em conta a percepção econômica sem a adequada incorporação dos aspectos ecológicos, tende a subestimar o VET dos ativos naturais. Assim, o MIAC recebeu uma força importante na sua validação, a partir do estudado de Kenneth Arrow e Robert Solow, dois ganhadores do Prêmio Nobel em Economia, com o objetivo de aferir o potencial da avaliação contingente como instrumento de estimação do valor de danos ambientais e do passivo pela perda de recursos naturais (ARROW et al., 1993). Uma das conclusões foi: 
[...] os estudos conduzidos com o método de avaliação contingente podem gerar estimativas confiáveis e suficientes como ponto de partida para uma decisão judicial ou administrativa sobre danos causados aos ativos ambientais, incluído os valores do passivo perdido (ARROW et al., 1993, p. 35).

O MIAC é o método mais adequado para estimar o valor de ativos naturais por incorporar o valor de opção e/ou de existência dos ativos ambientais (LOOMIS; WHITE, 1996; TURNER et al., 2003; CARSON, 2012; COSTANZA et al., 2014). Carson e Louviere (2011) identificaram mais de 7.500 artigos e estudos sobre a aplicação deste modelo em mais de 130 países, envolvendo aspectos culturais, ambientais, saúde, transporte, energia e outros, com diversos graus de integração entre os enfoques econômicos, sociodemográficos, sociais e ecológicos. Mesmo assim, algumas questões continuam sendo objeto de análise e discussão em pesquisas vinculadas ao potencial do método, com vistas a tornar os resultados válidos e confiáveis para estimar o valor econômico total dos ativos naturais.

Por fim, o ativo natural da canga não tem preço de mercado. Assim, para a estimativa de seu valor, aplicou-se o Método Integrado de Avaliação Contingente (MIAC) por contemplar, além das dimensões econômica (DECON) e sociodemográfica (DSDEM), as dimensões ambiental (DAMB) e ecológica (DECOL). Além disso, essas dimensões contêm as variáveis explanatórias das equações de valor da DAP, destinado à preservação do recurso, e de valor da DAR, utilizado para indenização à exploração do recurso, que estruturam o MIAC e têm os parâmetros estimados, simultaneamente, por mínimos quadrados generalizados.

O MIAC foi estruturado da seguinte forma (SANTANA, 2014):

MIAC

$$
\begin{aligned}
& D A P=f(D E C O N, D S D E M, D A M B, D E C O L ; \alpha) \\
& D A R=f(D E C O N, D S D E M, D A M B, D E C O L ; \beta)
\end{aligned}
$$

Em que $\alpha$ e $\beta$ são os vetores de parâmetros a serem estimados.

Portanto, ao fazer a integração das variáveis explanatórias associadas às dimensões econômicas e ecológicas e ao estimar os parâmetros das equações de DAR e DAP de forma simultânea, o MIAC pode gerar resultados robustos para as estimativas do valor do ativo natural da canga, tanto para preservar, quanto para suprimir a vegetação. 


\subsection{Questionamentos sobre a aplicação do MIAC}

A maior preocupação com o uso do método avaliação contingente está no fato de que os entrevistados da pesquisa tendem a emitir respostas enviesadas. Cinco tipos de vieses foram analisados por muitos pesquisadores (RANDALL; STOLL, 1980; HANEMANN, 1991; ARROW et al., 1993; HANEMANN, 1994; FARBER; COSTANZA; WILSON, 2002; PLOTT; ZEILER, 2011; ISONI, 2011; HAUSMAN, 2012; CARSON, 2012; SANTANA et al., 2015):

Viés estratégico: ocorre quando o entrevistado tem interesse em influenciar o resultado da pesquisa e atua para gerar um viés na resposta de modo a alterar o resultado final (BISHOP; ROMANO, 1998; PLOTT; ZEILER, 2005; CARSON; LOUVIERE, 2011; SANTANA et al., 2015). Ou seja, se o entrevistado imaginar que a decisão de preservar (explorar) a canga depende de um valor alto a ser indicado na pesquisa, pode atribuir um valor muito elevado, a ponto de enviesar o resultado final. Para diminuir esse tipo de erro, apresentou-se ao entrevistado uma tabela de valor da terra com diferentes usos na região de estudo (agricultura familiar, agricultura mecanizada, lavoura do cacau, pastagens de baixo rendimento, pastagens de alto rendimento, área de mata de difícil acesso, área de cerrado, área de mata de fácil acesso e área de mata com projeto de manejo florestal) para orientar a decisão sobre o valor a ser declarado pelo entrevistado. Essa estratégia funcionou como indicativo de um produto substituto da canga, uma vez que as terras ocupadas do entorno da Flona de Carajás um dia foram floresta e, atualmente, estão gerando renda para seus proprietários a partir dessas atividades. Além disso, foi esclarecido tudo sobre a pesquisa e sobre o ativo natural a ser valorado.

Viés de informação: pode ser originado quando o entrevistado é induzido a emitir a resposta desejada, ou seja, um produtor interessado em ter a área indenizada, ao interpretar que o resultado da pesquisa vai ser extrapolado para determinar o valor de suas terras, pode declarar um valor muito elevado para a disposição a receber e um valor zero para a disposição a pagar. Para atenuar esse tipo de viés, conforme Arrow et al. (1993), Bishop e Romano (1998), Carson (2012) e Ives e Kendal (2014), foram apresentados conceitos de canga, fotos sobre diversos aspectos da canga, suas características e suas potencialidades, inclusive, de conter espécies raras e/ou endêmicas, como a Flor de Carajás, de conter plantas utilizadas na fabricação de cosméticos, como o jaborandi, gramíneas, frutas, como o buriti, cavernas, áreas de turismo ecológico, rochas com o minério de ferro aflorando, além de verificar o conhecimento do entrevistado sobre questões climáticas, ecológicas, sociais e de potencial econômico da canga e das áreas do entorno da Flona de Carajás. 
Diferença entre o valor da DAP e da DAR: os entrevistados da avaliação contingente tendem, em geral, a atribuir um valor mais alto para a sua DAR do que para a DAP por uma melhoria específica em quantidade e qualidade. A teoria econômica sugere que os dois valores tendem a ser iguais (KRUTILLA, 1967; RANDALL; STOLL, 1980; HOEHN; RANDALL, 1987; HANEMANN, 1991; CARSON; MITCHELL, 1993; PLOTT; ZEILER, 2005; ISONI, 2011; CARSON; LOUVIERE, 2011; HAUSMAN, 2012; CARSON, 2012; SANTANA, 2015). Por outro lado, a experiência prática desenvolvida em vários trabalhos gerou resultados diferentes. As razões para essa diferença envolvem princípios econômicos e problemas com o desenho e a condução da pesquisa.

Muitos trabalhos aplicaram o método avaliação contingente, independente do grau de interação entre os princípios econômicos e ecológicos, para demonstrar a magnitude que essa diferença de resultado pode causar. Em função da importância do problema, Carson et al. (1998) avaliaram 1.672 trabalhos sobre a avaliação contingente, para investigar as causas do problema. Na verdade, a diferença entre o valor da DAP e da DAR tem sido a mais estudada e com regularidade nas últimas quatro décadas. A disparidade está documentada em muitos textos (BISHOP; ROMANO, 1998; PEARCE, 1990; HANEMANN, 1994; HOROWITZ; McCONNELL, 2002; FARBER; COSTANZA; WILSON, 2002; CARSON, 2012) e envolve desafios para a teoria hicksiana do consumidor e sua aplicação direta na estimação do VET. A maioria desses desafios teóricos já foi, em grande parte, equacionada, e continuam os estudos para tornar a avaliação contingente um método consolidado para a valoração de ativos naturais que não têm preço de mercado (CARSON; MITCHELL, 1993; CARSON; LOUVIERI, 2011; CARSON; CZAJKOWSKI, 2014; COSTANZA et al., 2014; SANTANA, 2014).

Para enfrentar a divergência entre a DAP pela preservação da área de canga e a DAR uma indenização pela supressão da canga, delimitou-se a área de estudo à escala da influência direta e indireta da Flona de Carajás, assim como o tempo de residência do entrevistado na área pesquisada, para assegurar conhecimento sobre a canga e a Flona de Carajás por parte da população local. As questões foram elaboradas de forma objetiva e clara, fotos foram apresentadas e uma tabela com os preços de terra com diversas utilizações (agricultura, pastagem, manejo florestal, matas) na área de estudo como referência, além de uma opção para o entrevistado indicar outro valor específico. 


\section{Metodologia de análise}

A área de pesquisa abrangeu a população residente e instituições a $200 \mathrm{~km}$ de distância da Flona de Carajás, contemplando os municípios de Parauapebas, Canaã dos Carajás e Curionópolis no estado do Pará (SANTANA, 2014).

Os dados utilizados na pesquisa foram obtidos a partir da aplicação de questionários com perguntas fechadas e abertas sobre as quatro dimensões a seguir:

a) A dimensão econômica e sociodemográfica dos entrevistados incluiu as variáveis: idade, sexo, tempo de residência no local, nível educacional, estado civil, tipo de atividade e suas principais fontes de renda, conflitos de terra, negociação de venda e indenização de terra, infraestrutura de estradas e transportes e a disponibilidade dos serviços públicos (educação, saúde e segurança);

b) A dimensão ambiental incluiu as seguintes variáveis: variação climática, conservação da floresta, utilização de queimadas, desmatamento, utilização de agrotóxico, utilização de técnicas para o desenvolvimento sustentável, caça e/ou pesca predatória, potencialidade de uso sustentável e/ou preservação da flora e da fauna, qualidade da água dos rios e nascentes, belezas cênicas naturais;

c) A dimensão ecológica, dada pelas características, potencialidades e riqueza da Flona de Carajás, contemplou as seguintes variáveis: espécies florestais de valor comercial, abundância de animais selvagens para caça, existência de espécies raras e/ou endêmicas, extração de produtos florestais não madeireiros, extração de produtos madeireiros, nascentes e cachoeiras com potencial para o turismo ecológico;

d) A dimensão de valor econômico da área de canga contemplou: os tipos potenciais de utilização da canga como pastagem para criação de gado, a prestação de serviços turísticos, a disposição a pagar pela preservação e a disposição a receber como indenização pela supressão da vegetação da canga.

Estas dimensões, contemplando os fundamentos econômicos e ecológicos, permitiu especificar o MIAC para estimar o valor da canga (CONTANZA et al., 1997; RICHARDES; LOOMIS, 2009; COSTANZA et al., 2014; SANTANA et al., 2015; SANTANA et al., 2016). Dessa forma, o fluxo de produtos e serviços dos ecossistemas foi incluído nas preferências declaradas pelas pessoas entrevistadas sobre $o$ valor econômico da canga. 
As entrevistas foram realizadas por uma equipe de profissionais que informou e esclareceu aos entrevistados o objetivo do trabalho, apresentou as características, as formas de utilização e as potencialidades da área de canga e suas relações com as comunidades do entorno. Com isto, foram ofertadas as condições necessárias e/ ou suficientes para que o entrevistado tomasse a decisão de atribuir valor monetário à vegetação da área de canga.

Os valores da Disposição a Pagar (DAP) pela preservação da canga e da Disposição a Receber (DAR) uma indenização pela supressão da vegetação da canga, na percepção dos entrevistados, que são as variáveis dependentes das equações utilizadas na estimação do valor econômico total, foram obtidos das resposta às seguintes questões (SANTANA, 2014):

DAP - Com base na definição de canga, nas fotos apresentadas e em seu conhecimento sobre a importância da Flona de Carajás, considerando a vegetação, espécies raras e/ou endêmicas, cavernas, o minério de ferro e o turismo, bem como as atividades do seu entorno, o valor das terras ocupadas com agricultura, pecuária e mata que foram apresentadas, declare qual o valor máximo que está disposto a pagar para manter a canga preservada da forma como está sendo utilizada pela população local.

DAR - Admitindo que você tenha o direito exclusivo de utilização da área de canga, considerando a vegetação, espécies raras e/ou endêmicas, cavernas, o minério de ferro e o turismo, bem como as atividades do seu entorno, o valor das terras ocupadas com agricultura, pecuária e mata que foram apresentadas, declare qual o valor mínimo que está disposto a receber como uma indenização para que o comprador a explore da forma como desejar.

Para auxiliar o entrevistado a emitir uma resposta consistente com o valor monetário da vegetação de canga, forneceu-se uma tabela com as faixas de valores correspondentes ao preço de terras com agricultura (familiar, com cacau e mecanizada), pastagens (baixo suporte e de alta produtividade) e matas (difícil acesso, fácil acesso e manejada), praticados na microrregião de Parauapebas e em outras áreas sob a influência de grandes empreendimentos. Incluiu-se, também, o valor de terras indenizadas pela Vale em algumas vilas da área de pesquisa. Essa informação foi estratégica para facilitar a decisão do entrevistado, sobretudo daqueles que não conheciam a área de canga da Flona de Carajás e que apresentavam menor grau de conhecimento sobre a preservação dos recursos naturais e sua contribuição para a biodiversidade, regulação do clima e dos mananciais de água de rios e igarapés da região. 
Escolhida a opção, o entrevistado foi estimulado a informar se o valor declarado corresponde à média, situa-se acima ou abaixo da média ou, ainda, indicar um outro valor. Essa estratégia foi importante para dar maior variabilidade aos dados e permitir maior consistência às estimativas dos parâmetros do modelo econométrico.

Os questionários foram aplicados a uma amostra representativa da população, direta e indiretamente influenciada pela Flona de Carajás e pelas atividades desenvolvidas na extração de minérios. A partir de informações fornecidas pela Vale e pelos grupos de interesse, durante o trabalho de reconhecimento da área, a população foi constituída pelo número de famílias residentes, distribuídas em vinte vilas, eleitas com base no fundamento da escala de proximidade, conhecimento, tempo de moradia e convivência com as dinâmicas do desenvolvimento local. Essa estratégia, conforme Ives e Kendal (2014), tornam as decisões relativamente estáveis sobre o valor monetário do ativo natural. O tamanho da amostra foi determinado com base na seguinte fórmula (SANTANA et al., 2014):

$$
n=\frac{p \cdot q \cdot z^{2} \cdot N}{e^{2}(N-1)+p \cdot q \cdot z^{2}}
$$

Em que: $N$ é tamanho da população residente nas vilas de 8.956 famílias; $p$ é a proporção em que a característica a ser pesquisada apresenta-se no universo das 8.956 famílias com possibilidade de serem entrevistadas, igual a $50 \%$ favoráveis a declarar a preferência pela valoração da canga e 50\% desfavoráveis, ou seja, trabalha-se com a maior variância possível para assegurar confiabilidade, dado tratar-se de pesquisa de opinião; $q=(1-p)$ e $p . q=0,25$, que gera o $n$ máximo sob a condição ( $n . p \geq 5$ e $n . q \geq 5$ ); $z$ é o desvio padrão associado ao índice de confiança, considerado de $95 \%$, igual a 1,96, plenamente aceitável nesse tipo de pesquisa; $e$ é o erro amostral de estimação de 5\%, que é o valor de tolerância em relação aos resultados da pesquisa; e $n$ é o tamanho da amostra ou o número mínimo de pessoas a serem entrevistadas.

\subsection{Modelo econométrico}

A conexão sistêmica entre as mudanças no meio ambiente e na qualidade de vida da população exige decisões que otimizem a combinação dos ativos naturais e ativos fixos com vistas a maximizar o bem-estar social (RANDALL; STOLL, 1980; RANEMANN, 1994; COSTANZA et al., 1997; SANTANA, 2014). Sendo assim, a 
declaração de preferência da população para preservar um ativo natural ou para receber uma compensação pela supressão ou perda do recurso natural, configurada na interdependência nas funções de DAP e DAR, deve ser especificada por um sistema de equações e seus parâmetros estimados de forma simultânea por mínimos quadrados generalizados.

O modelo econométrico de valoração da canga foi especificado por um sistema de equações aparentemente não relacionadas (SANTANA, 1999), formado pelas equações da disposição a pagar pela preservação e a disposição a receber uma indenização pela supressão da vegetação da canga. Nesse modelo, assumiu-se que os termos de erro das equações estão correlacionados, dada a simultaneidade das opções de decisão do entrevistado para pagar pela preservação ou receber compensação pela diminuição do estoque do recurso natural. Assim, a estimação separada de cada equação não considera a informação sobre a correlação mútua dos termos de erro, e a eficiência dos estimadores torna-se questionável (KMENTA, 1978).

O sistema de equações aparentemente não relacionadas, conhecido na literatura como modelo SUR (Seemigly Unrelated Regressions), na forma irrestrita é dado por Greene (2011):

$$
Y_{m}=\beta_{m} X_{m}+u_{m}(m=1,2)
$$

Na equação $2, Y_{m}$ representa o vetor de dimensão $\left(\begin{array}{lll}T & x & 1\end{array}\right)$ das observações amostrais das variáveis dependentes (DAP e DAR); $X_{m}$ representa a matriz ( $T \times K_{m}$ ) com os valores das observações das variáveis explanatórias correspondentes aos fatores sociodemomográficos, econômicos, ambientais e ecológicos; $\beta_{m}$ é um vetor $\left(K_{m} x 1\right)$ dos parâmetros das equações a serem estimados e $u_{m}$ é um vetor ( T x 1) dos valores amostrais dos erros aleatórios. O erro $u_{m}$ apresenta distribuição normal com média $E\left(e_{m t}\right)=0$, para $(t=1,2, \ldots, T)$ e a matriz de variância e covariância é dada por $E\left(u_{m}, u_{m}^{\prime}\right)=\sigma_{m m} I_{T}$.

Adicionalmente, assume-se que os erros das equações não são mutuamente exclusivos. Assim, tem-se que a matriz de variância e covariância com os erros das equações apresentam vínculos, e o sistema, conforme Kmenta (1978), é aparentemente não correlacionado com a matriz de variância e covariância dada por:

$$
E\left(u_{m}, u_{p}^{\prime}\right)=V=\Sigma \otimes I=\sigma_{m p} I_{T}, \operatorname{com}(m, p=1,2, \ldots, T) \text { e } V^{-1}=\Sigma^{-1} \otimes I
$$


Conforme Greene (2011) e Eviews7 (2012), o vetor dos parâmetros estimados de forma não tendenciosa é dado pela fórmula de mínimos quadrados generalizados:

$$
\beta=\left(X^{\prime} V^{-1} X\right)^{-1} X^{\prime} V^{-1} Y=\left[X^{\prime}\left(\Sigma^{-1} \otimes I\right) X\right]^{-1} X^{\prime}\left(\Sigma^{-1} \otimes I\right) Y
$$

O modelo não apresenta problema de autocorrelação serial nos resíduos, uma vez que a amostra de dados é de seção cruzada. O modelo foi especificado da seguinte forma (SANTANA, 2014):

$$
\begin{aligned}
& D A P_{i}= \\
& b_{10}+b_{11} R D_{i}+b_{12} E D U_{i}+b_{13} T P M_{i}+b_{14} S X_{i}+b_{15} I D A M B_{i} \\
& +b_{16} I D E C O L_{i}+b_{17} I D A D_{i}+b_{18} T_{F a m_{i}}+b_{19} V D_{i}+e_{i 1} \\
& D A R_{i}= \\
& b_{20}+b_{21} R D_{i}+b_{22} E D U_{i}+b_{23} T P M_{i}+b_{24} S X_{i}+b_{25} I D A M B_{i} \\
& +b_{26} I_{D E C O L}+b_{27} I D A D_{i}+b_{28} \text { TFam }_{i}+b_{29} V D_{i}+e_{i 2} \\
& i=1, \ldots, N ; e_{i} \sim N\left(0, \sigma^{2}\right)
\end{aligned}
$$

em que $D A P_{i}$ é a preferência declarada do entrevistado $i$ pela disposição a pagar um valor monetário para manter preservada a área de canga da Flona de Carajás, em $\mathrm{R} \$ /$ ha; $D A R_{i}$ é a preferência declarada do entrevistado $i$ pela disposição a receber uma indenização pela supressão da área de canga da Flona de Carajás, em $\mathrm{R} \$ /$ ha; $R D_{i}$ é a renda média do entrevistado $i$, em $\mathrm{R} \$ /$ mês, e deve apresentar uma associação positiva com a variável dependente, porque as pessoas com rendas mais elevadas tendem a declarar uma propensão a pagar (receber) valores mais elevados pela preservação (exploração) do recurso natural; $E D U_{i}$ é o nível de educação do entrevistado $i$, em anos de escolaridade, e deve apresentar uma relação positiva com a variável dependente, porque o maior domínio de informação e conhecimento sobre os recursos naturais pode estimular a disposição a pagar (receber) um valor mais alto; $T P M_{i}$ é o tempo de moradia do entrevistado $i$ no local da pesquisa, em anos, e espera-se uma associação positiva com a variável dependente; $S X_{i}$ é o sexo do entrevistado $i$, assumindo valor 1 para masculino e zero para feminino, e a relação pode ser positiva ou negativa; $I D A M B_{i}$ é o indicador da dimensão ambiental 
da área de estudo na percepção do entrevistado $i$, elaborado a partir da análise fatorial aplicada a dez variáveis (SANTANA, 2014), em que o efeito sobre a variável dependente pode ser positivo ou negativo; $I D E C O L_{i}$ é o indicador da dimensão ecológica da Flona de Carajás e da área do entorno na percepção do entrevistado $i$, gerado, a partir da análise fatorial aplicada, nove variáveis (SANTANA, 2014), em que o efeito sobre a variável dependente pode ser positivo ou negativo; $I D A D_{i}$ é a idade do entrevistado $i$, em anos, e a associação pode ser positiva ou negativa; TFam $_{i}$ é o tamanho da família $i$, em número de pessoas, cujo sinal esperado para o coeficiente deve ser negativo; $V D_{i}$ é uma variável dummy que assume valor um para os entrevistados que conhecem a área de canga e atribuíram um valor da DAP (DAR) superior a $R \$ 3.000,00 /$ ha, cujo sinal esperado é positivo; $b_{1 i}$ e $b_{2 i}$ são os parâmetros a serem estimados por mínimos quadrados ordinários por meio do Eviews7; e $e_{i 1}$ e $e_{i 2}$ são os termos de erro aleatórios das equações da DAP e DAR.

\section{Resultados e discussão}

Os resultados foram analisados e discutidos a fim de estimar o valor econômico total da vegetação de canga da Flona de Carajás.

O tamanho mínimo da amostra representativa foi definido em 369 famílias, e o total de questionários válidos obtidos na pesquisa de campo foi de 442 , o que aumentou a segurança do trabalho.

Com relação ao sexo, a amostra apresentou-se simetricamente dividida, com $50,9 \%$ do sexo masculino e $49,1 \%$ do sexo feminino. Essa variável é considerada relevante para o método de avaliação contingente, porém os resultados empíricos, em geral, não apresentam significância estatística.

Sobre a idade do entrevistado, obteve-se uma concentração de entrevistados de até 45 anos, representados por 60,86\% do total. Entre esses, 23,98\% estão na faixa de 18 a 30 anos. Com mais de 45 anos e menos de 65, foram entrevistados $30,77 \%$ pessoas. Os sujeitos com pelo menos 65 anos representaram 8,37\% da amostra. Todos os entrevistados manifestaram concordância e capacidade para responder às perguntas sobre as mudanças nas condições ambientais e ecológicas da área de pesquisa, bem como declarar sua preferência com relação à preservação e/ou supressão da vegetação de canga da Flona de Carajás.

O nível de educação também é considerado uma variável importante para determinar e qualificar a valoração dos recursos naturais e, especificamente, declarar um valor para a canga. Entre os entrevistados o nível de escolaridade ainda é 
baixo, dado que $45,48 \%$ deles cursaram até o ensino fundamental, sendo que $36,2 \%$ ainda não completaram esta etapa do estudo, e $2,8 \%$ são analfabetos.

Por fim, a renda média mensal per capita das pessoas entrevistadas foi de $\mathrm{R} \$ 2.147,49$, com desvio padrão de $\mathrm{R} \$ 1.722,75$. Nesta distribuição assimétrica, $21,5 \%$ das pessoas ganham pelo menos $R \$ 3.000,00$ por mês e $28,3 \%$ têm renda inferior a $\mathrm{R} \$ 1.000,00 /$ mês.

\subsection{Valor econômico total da vegetação de canga}

Na Tabela 1, apresentam-se os resultados do MIAC para a vegetação de canga da Flona de Carajás, com base nas preferências declaradas pelos entrevistados sobre a DAP para manter a canga preservada e a DAR para obter uma indenização pela supressão da vegetação e permitir a exploração da área.

As variáveis sexo e idade foram incluídas no modelo por expressarem os aspectos de gênero e de demografia das populações investigadas. Contudo, os resultados encontrados para tais variáveis não apresentaram significância estatística na equação da disposição a pagar, em concordância com Baral, Stern e Bhattarai (2008), Ortiz, Motta e Ferraz (2001) e Bentes et al. (2014). Com relação à variável idade, Amirnejad et al. (2006) encontraram um valor negativo, indicando que as pessoas mais jovens apresentaram a disposição a pagar um valor mais alto pela existência da floresta. Igualmente, Adams et al. (2008) e Subade e Francisco (2014) obtiveram um sinal negativo da idade em relação ao valor da DAP, respectivamente, para a preservação da Mata Atlântica do Parque do Morro do Diabo, em São Paulo, e a conservação dos corais de recifes, nas Filipinas.

A variável tamanho da família, que reflete uma característica sociodemográfica da população, embora menos frequente nos estudos, geralmente não apresenta significância estatística, como observado por Rhee (2013), em estudo sobre a disposição a pagar para evitar doenças infecciosas causadas por mudanças climáticas, e Abdullah e Jeanty (2011), na pesquisa sobre DAP por energia renováveis. Por outro lado, Baral, Stern e Bhattarai (2008), em pesquisa sobre a avaliação da DAP pelos visitantes de uma área de ecoturismo no Nepal, encontraram um sinal negativo e significativo para o tamanho da família, indicando que, quanto maior o tamanho da família, menor a DAP um valor alto. Este resultado é coerente com o fato de que, para as famílias numerosas e pobres, o custo de vida torna-se mais alto e a disposição a pagar valores adicionais diminui.

Assim, após a retirada das variáveis não significativas, o sistema de equações com as variáveis relevantes não apresentou problema de autocorrelação 
contemporânea e nem de multicolinearidade. O problema da heterocedasticidade, que é comum a amostras de dados de seção cruzada, foi equacionado por meio da estimação dos parâmetros por mínimos quadrados generalizados no Eviews7. Adicionalmente, em todos os trabalhos consultados, os parâmetros das equações de DAP e DAR foram estimados de forma separada. Portanto, além de se tratar de iniciativa pioneira deste trabalho, a estimação simultânea dos parâmetros do sistema de equações aparentemente não relacionadas gerou estimativas não viesadas e eficientes para os parâmetros.

\subsection{Disposição a pagar e disposição a receber pela canga}

As equações da DAP e da DAR apresentaram-se válidas para representar a preferência declarada pelos entrevistados sobre o valor da canga (Tabela 1). As variáveis explanatórias explicaram $91,66 \%$ e 87,90\%, respectivamente, das variações no valor da disposição a pagar e no valor da disposição a receber. Este resultado, juntamente com a significância da estatística $F$ a $1 \%$, indica que o conjunto de variáveis explanatórias valida a especificação das equações de DAP e DAR. Esse é um forte indicativo de que o valor estimado, a partir da DAP pela preservação e da DAR pela supressão da canga, mantém forte aderência com o valor real de mercado de terras do bioma Amazônia da área de Carajás.

Os parâmetros associados às variáveis foram todos significativos a $1 \%$ para a DAP e a $1 \%, 5 \%$ e $8,76 \%$ para a DAR. As variáveis dependentes DAP e DAR mantiveram correlação direta com todas as variáveis explanatórias, indicando que as mudanças nas condições observadas nas variáveis produzem alteração na variável dependente e na mesma direção, de acordo com o resultado teoricamente esperado (Tabela 1).

O efeito da renda individual dos entrevistados exibiu um resultado de acordo com o justificado pela teoria, uma vez que, em geral, pessoas com rendas mais altas têm uma predisposição a pagar (receber) um valor mais elevado para preservar (explorar) um recurso natural.

Neste trabalho, um incremento de $\mathrm{R} \$ 1.000,00$ na renda do entrevistado tende a gerar um aumento de $\mathrm{R} \$ 520,87$ na DAP por cada hectare de canga, ceteris paribus. Da mesma forma, tende a gerar um aumento no valor médio da DAR de $\mathrm{R} \$ 877,27$ por cada hectare de canga a ser indenizado. 
Tabela 1 - Resultados das estimativas dos parâmetros das equações da disposição a pagar e da disposição a receber pelo ativo ambiental da canga da Flona de Carajás, estado do Pará

\begin{tabular}{|c|c|c|c|c|}
\hline \multicolumn{5}{|c|}{$\begin{array}{l}\text { Método de Estimação: Regressões Aparentemente não Relacionadas; Amostra: 442; } \\
\text { Número Total de Observações do Sistema Equilibrado: } 884 \text { (EVIEWS7, 2012). }\end{array}$} \\
\hline Variável & Coeficiente & Estatística t & Probabilidade & $\mathrm{DAP}(\mathrm{R} \$ / \mathrm{ha})$ \\
\hline Intercepto $-\boldsymbol{b}_{10}$ & 640,9696 & 6,657739 & 0,0000 & 640,97 \\
\hline Renda individual $-\boldsymbol{b}_{11}$ & 0,52087 & 26,00965 & 0,0000 & $1.118,56$ \\
\hline Educação - $\boldsymbol{b}_{12}$ & 51,2706 & 3,424116 & 0,0006 & 162,51 \\
\hline Variável dummy - $\boldsymbol{b}_{13}$ & 1005,663 & 16,17068 & 0,0000 & $1.005,66$ \\
\hline Indicador Potencial da Flona - $\boldsymbol{b}_{14}$ & 602,4324 & 4,115261 & 0,0000 & 365,79 \\
\hline Indicador Ambiental - $\boldsymbol{b}_{15}$ & 762,8149 & 3,961825 & 0,0001 & 467,85 \\
\hline Tempo que Mora no Local - $\boldsymbol{b}_{16}$ & 20,43851 & 5,511602 & 0,0000 & 312,5 \\
\hline \multicolumn{4}{|c|}{ Valor Econômico Total da $D A P(R \$ / h a)$ pela canga - MIAC = } & $4.073,84$ \\
\hline Variável & Coeficiente & Estatística t & Probabilidade & $\mathrm{DAR}(\mathrm{R} \$ / \mathrm{ha})$ \\
\hline Intercepto $-\boldsymbol{b}_{20}$ & 601,9792 & 3,956352 & 0,0001 & 601,98 \\
\hline Renda Familiar - $\boldsymbol{b}_{21}$ & 0,877265 & 27,71789 & 0,0000 & $1.883,92$ \\
\hline Educação - $\boldsymbol{b}_{22}$ & 40,47178 & 1,710238 & 0,0876 & 128,28 \\
\hline Variável dummy - $\boldsymbol{b}_{23}$ & 738,3309 & 7,511922 & 0,0000 & 738,33 \\
\hline Indicador Potencial da Flona $-\boldsymbol{b}_{24}$ & 579,477 & 2,504664 & 0,0124 & 351,85 \\
\hline Indicador Ambiental - $\boldsymbol{b}_{25}$ & 632,0567 & 2,077095 & 0,0381 & 387,65 \\
\hline Tempo Mora Local - $\boldsymbol{b}_{26}$ & 21,16091 & 3,610666 & 0,0003 & 323,54 \\
\hline \multicolumn{4}{|c|}{ Valor Econômico Total da $D A R(R \$ / h a)$ pela canga - MIAC = } & $4.415,56$ \\
\hline R-Quadrado Ajustado: $\boldsymbol{D A P}$ & 0,916437 & \multicolumn{2}{|c|}{ Média da var. dependente } & 3575,564 \\
\hline R-Quadrado Ajustado: $\boldsymbol{D A R}$ & 0,879058 & \multicolumn{2}{|c|}{ Média da var. dependente } & 4049,733 \\
\hline Estatística F: DAP & $484,67(p<0,01)$ & \multicolumn{2}{|c|}{ Estatística F: DAR } & $322,38(p<0,01)$ \\
\hline
\end{tabular}

Fonte: dados da pesquisa.

Resultados similares para a DAP foram encontrados por: Groot et al. (2012), na estimativa do valor global de ecossistemas; Santana et al. (2015), no trabalho sobre o valor econômico total dos danos potenciais a serem causados pelos empreendimentos em hidrelétricas, previstos para a bacia do rio Tapajós, estado do Pará, sobre pescadores e agricultores familiares; Abdullah e Jeanty (2011), no estudo sobre DAP por energia renováveis; Ortiz, Motta e Ferraz (2001), na pesquisa sobre o valor ambiental do Parque Nacional do Iguaçu; Amirnejad et al. (2006), no artigo sobre o valor de existência de uma floresta no norte do Irã; Adams et al. (2008), no trabalho sobre a preservação da Mata Atlântica brasileira; Khan, Brouwer e 
Yang (2014), no artigo sobre a contaminação de água potável por arsênico em Bangladesh; Subade e Francisco (2014), na pesquisa sobre a conservação de corais de recifes nas Filipinas; e Veronesi et al. (2014), no estudo sobre a redução de riscos ecológicos e de saúde da população da Suíça, resultantes de mudanças climáticas.

Os dados sobre a educação revelou que um maior nível de escolaridade está associado à disposição a pagar (receber) valores mais elevados pela preservação (exploração) dos ativos naturais. Isso porque a educação está relacionada a maior conhecimento sobre o ativo ambiental, a ganhos de produtividade e a um maior nível de conscientização acerca da importância que a preservação e/ou exploração dos recursos naturais apresentam para o desenvolvimento local.

Com efeito, tem-se que, para cada ano adicional de estudo que a pessoa cursou, a DAP tende a ser incrementada em $\mathrm{R} \$ 51,27 /$ ha de canga preservada, enquanto que a DAR pode ser aumentado em $R \$ 40,47 /$ ha de canga a ser suprimida, ceteris paribus.

Alguns estudos sobre DAP obtiveram resultados significativos para educação. Entre eles tem-se: Bentes et al. (2014), no trabalho sobre o valor econômico e ambiental dos danos causados pela Usina Hidrelétrica de Tucuruí sobre os pescadores da jusante do rio Tocantins no estado do Pará; Lera-López, Faulin e Sánchez (2012), no estudo da DAP pela redução dos impactos ambientais produzidos pelo transporte rodoviário; Abdullah e Jeanty (2011), na pesquisa sobre DAP por energia renováveis; Adams et al. (2008) e Amirnejad et al. (2006), respectivamente, nas pesquisas sobre o valor da DAP pela preservação da Mata Atlântica e pela existência de uma área de floresta no Irã. Por outro lado, nos estudos de Barral (2008), Subade e Francisco (2014) e Veronesi et al. (2014), a variável não apresentou significância estatística, embora com sinal positivo.

O resultado da variável dummy, que capta o efeito da distribuição de poder aquisitivo dos entrevistados, indicam que as pessoas com maior poder aquisitivo e acúmulo patrimonial tendem a pagar um valor acima da média do valor pago pelas pessoas mais pobres. Esse conjunto de pessoas com maior renda tem maior potencial para realizar investimentos e contribuir com o crescimento da economia local. Portanto, conforme Tisdell (2011), essas pessoas tendem a responder pela transformação socioeconômica e ambiental da região e, como as atividades agropecuárias e florestais necessitam de escala para aumentar o retorno, apresentam predisposição a pagar (receber) um valor mais alto para preservar (explorar) os recursos naturais e diminuir (aumentar) a pegada ecológica.

A maioria dos estudos utiliza variável dummy para captar diversos efeitos sobre a DAP, mas são raros os que se preocupam com o efeito da acumulação de 
capital ou a concentração da renda. Entre estes, Santana et al. (2015) encontraram resultado semelhante entre as pessoas com disposição a pagar pela preservação da bacia do rio Tapajós. Nesta pesquisa, os entrevistados que declararam a DAP ou a DAR um valor acima de $\mathrm{R} \$ 3.000,00 /$ ha, diferenciaram-se do restante, respectivamente, em $R \$ 1.005,66 /$ ha e em $R \$ 738,33 /$ ha acima da média declarada pelos demais entrevistados. Portanto, a acumulação de capital causa um significativo impacto sobre a valoração da canga, tanto para preservar, quanto para explorar, mesmo que isto implique aumento da pegada ecológica.

Com relação ao tempo que a pessoa reside no local, o resultado indicou que, na situação da área de influência da Flona de Carajás, onde estão os projetos de extração dos minérios de fero, cobre e manganês, quanto maior o tempo de residência no local, maior foi a predisposição a pagar (receber) um valor mais alto pela preservação (exploração) da canga. Um maior tempo de vivência na região significa maior acúmulo de informação, conhecimento e conscientização sobre a conservação e/ou uso dos recursos naturais, de modo a justificar uma maior disposição a pagar (receber) pelos recursos naturais. Portanto, evidenciou-se que, a cada ano adicional ao tempo médio de residência no local, o entrevistado tende a aumentar o valor médio da DAP e da DAR, respectivamente, em $\mathrm{R} \$ 20,44 /$ ha e $\mathrm{R} \$ 21,16 /$ ha (Tabela 1 ).

O número de trabalhos que incluiu essa variável na análise é pequeno. Entre eles, a maior parcela utiliza a variável idade e, em todos os trabalhos consultados, não apresenta significância estatística, como é o caso de Ortiz, Motta e Ferraz (2001), que encontraram correlações positivas e negativas para a idade, embora não significantes; e de Bentes et al. (2014), que obtiveram uma relação negativa e não significativa. $O$ único trabalho que incluiu essa variável na determinação da DAP foi o de Abdullah e Jeanty (2011), cujo resultado apresentou sinal negativo e não significante.

Por fim, das variáveis que representam a influência dos fatores ambientais e o potencial ecossistêmico da vegetação de canga da Flona de Carajás e que definem uma visão holística sobre a valoração da natureza pelo MIAC para fins de preservação dos geoambientes da canga, como analisado nesta pesquisa, não foi encontrado nada parecido na literatura. Os mais disseminados são os modelos que usam variáveis dummy para captar efeitos específicos de funções ambientais, considerados relevantes em cada caso (SANTANA, 2014). Contudo, muitas variáveis dummy incluídas em uma equação tendem a apresentar problemas de forte multicolinearidade, que inviabilizam o cálculo da contribuição individual de cada variável, além de tornar muitos parâmetros não significativos e alguns com sinais trocados. Aliás, essa foi uma deficiência encontrada nos trabalhos incluídos nesta discussão. 
Para evitar esses problemas e representar adequadamente a influência dos fatores econômicos, sociodemográficos, ambientais e ecológicos na estimação do valor da DAP e da DAR foram utilizados indicadores, elaborados com a aplicação da análise de componentes principais, a partir do conjunto de dez variáveis ambientais e nove variáveis de potencial ecológico da Flona de Carajás. Com isto, incorporou-se o valor monetário da multifuncionalidade dos ativos naturais no sistema econômico, que tende a apresentar uma correlação positiva com o crescimento das atividades produtivas e que deve ser traduzido na disposição a pagar valores mais altos pela preservação e/ou pelo uso sustentável dos recursos naturais.

Na Tabela 1, o incremento de uma unidade no valor médio destes indicadores, respectivamente, tende a gerar um aumento de $R \$ 602,43 /$ ha e $R \$ 762,81 /$ ha no valor da DAP pela preservação da canga. Com efeito, o aumento de uma unidade nesses indicadores resulta em incremento de $R \$ 738,33 /$ ha e $R \$ 632,06 /$ ha no valor da DAR, como indenização pela exploração da área de canga. Ressalta-se que uma unidade de valor destes índices equivale a $100 \%$ de aumento na DAP (DAR), dado que variam entre zero e um.

Dessa forma, o valor médio estimado da DAP para preservar o ecossistema da área de canga foi de $R \$ 4.073,84 /$ ha (com valor máximo de $R \$ 4.521,62 /$ ha), e o valor da DAR para indenizar pela supressão da vegetação de canga, de $\mathrm{R} \$ 4.415,56 / \mathrm{ha}$ (com valor máximo de $\mathrm{R} \$ 5.170,66 / \mathrm{ha}$ ). Esses resultados são compatíveis com o valor líquido de um fluxo líquido de benefícios, conforme Hoehn e Randall (1989), Hanemann (1994), Loomis e White (1996), Contanza et al. (1997), Torras (2000), Farber, Costanza, Wilson (2002), Costanza et al. (2014), Santana et al. (2015) e Santana et al. (2016).

Portanto, assumindo o custo de oportunidade do capital investido em atividades alternativas de $12,0 \%$ ao ano, tem-se uma anuidade no valor da DAP de $\mathrm{R} \$ 488,86 / \mathrm{ha} /$ ano. Esse valor é compatível com o encontrado por Adams et al. (2008), de $\mathrm{R} \$ 327,05 /$ ha/ano (valor atualizado em abril de 2014), para preservar o Parque do Morro do Diabo em Teodoro Sampaio, no estado de São Paulo. Também é compatível com a rentabilidade da pecuária de corte ( $R \$ 360,00 / \mathrm{ha} / \mathrm{ano})$ e agricultura de grãos ( $R \$ 400,00 /$ ha/ano), conforme Santana (2014).

Seidl e Moraes (2000), no estudo sobre o valor global dos serviços ecossistêmicos do Pantanal, encontraram um valor médio de $\mathrm{R} \$ 13.038,75 /$ ha, considerado extremamente elevado em relação ao preço de mercado das atividades desenvolvidas na área de estudo, em que o valor da pastagem variou entre $R \$ 223,28 /$ ha e $\mathrm{R} \$ 669,83 /$ ha e o valor presente líquido da pecuária foi de $\mathrm{R} \$ 446,55 /$ ha (valores de abril de 2014). Sutton e Costanza (2002) utilizaram, entre outros, o método da 
avaliação contingente para estimar o valor global de mercado e de não mercado dos serviços ecossistêmicos produzidos por diversos biomas, entre eles, o de savana, e o valor encontrado foi de $\mathrm{R} \$ 518,00 /$ ha (valores de abril de 2014).

Com relação ao valor da DAR pela supressão da canga, nenhum estudo foi encontrado. Todavia, Costanza et al. (1997) e Sutton e Costanza (2002) estimaram o valor monetário para a vegetação de gramíneas do bioma global de savana em $\mathrm{R} \$ 518,00 /$ ha (valores de abril de 2014). É um valor subestimado, porque não foram computados os demais geoambientes ou fitofisionomias da savana, para efeito de comparação com o valor agregado do ecossistema de canga estimado no trabalho.

Com efeito, o mercado real de terras com vegetação comparável com o bioma da área de pesquisa e de situações de áreas sob a influência de projetos envolvendo a implantação de florestas de eucalipto, cultivo de dendê e usinas para a produção de energia elétrica no estado do Pará, está operando com os preços médios: terra com agricultura familiar, $\mathrm{R} \$ 1.250,00 / \mathrm{ha}$; terra com agricultura mecanizada, $\mathrm{R} \$ 3.400,00 /$ ha; terra cultivada com cacau na área de influência da Usina Hidrelétrica (UHE) de Belo Monte, $\mathrm{R} \$ 5.100,00 /$ ha; terra com pastagem de baixo suporte, $\mathrm{R} \$ 1.700,00 /$ ha; terra com pastagem de alto suporte, $R \$ 3.550,00 /$ ha; terra de mata com difícil acesso, $\mathrm{R} \$ 1.600,00 /$ ha; terra de mata com fácil acesso, $\mathrm{R} \$ 2.270,00 / \mathrm{ha}$; e terra de mata com projeto de manejo, $\mathrm{R} \$ \mathrm{R} \$ 2.750,00 /$ ha (SANTANA; SANTOS; SANTANA, 2014; IFNP, 2014; SANTANA, 2014). Portanto, no estado do Pará, as terras de maior valor comercial são as de elevada fertilidade natural, que estão ocupadas com lavoura de cacau e sob o efeito da indenização pela UHE de Belo Monte.

$\mathrm{Na}$ área de pesquisa, o preço de terra com agricultura e pastagens, em abril de 2014 , momento da pesquisa de campo, variou entre $R \$ 2.500,00 /$ há, na área rural das vilas Paulo Fonteles e Sansão, e R $\$ 4.000,00 /$ ha, na zona rural das vilas Palmares II, Ouro Verde, Planalto e Racha Placa. Esse valor capta a influência da indenização de terras na vila Racha Placa pela VALE, no período da pesquisa de campo.

O valor de venda das terras da região de Balsas, no Maranhão, cuja vegetação é comparável com a da canga da Flona de Carajás, variou entre $\mathrm{R} \$ 640,00 /$ ha, para o cerrado não agrícola, e $\mathrm{R} \$ 3.650,00 /$ há, para o cerrado utilizado na produção de soja (SANTANA; SANTOS; SANTANA, 2014; IFNP, 2014). Assim, o valor médio de $\mathrm{R} \$ 4.415,56 /$ ha da DAR pela vegetação da canga indica que os respondentes avaliaram esse ativo natural como um substituto relativamente próximo das terras mais produtivas e valorizadas da área de estudo e das regiões sob a influência de grandes projetos de desenvolvimento. 


\subsection{Relação entre os valores da DAP e DAR}

Os valores da DAP e DAR foram definidos, respectivamente, pela contribuição das dimensões econômica (renda familiar e distribuição de renda), sociodemográfica (educação e tempo no local), dimensão ambiental e ecológica (indicador ambiental e indicador ecológico) e dimensão tácita (valor médio captado pelo intercepto).

A dimensão econômica contribuiu com $52,1 \%$ do valor da DAP e com 59,4\%, do valor da DAR, e a dimensão sociodemográfica contribuiu com $11,7 \%$ para o valor da DAP e 10,2\% para o valor da DAR. Em conjunto, essas dimensões representaram $62,8 \%$ e $69,7 \%$, respectivamente, do valor da DAP e DAR. Não obstante, esse peso hegemônico na composição do valor econômico total desse ativo natural, a incorporação das dimensões ambiental e ecológica respondeu, respectivamente, por $20,5 \%$ do valor da DAP pela preservação e $16,8 \%$ do valor da DAR pela supressão da vegetação de canga. A componente tácita, que capta a forma intrínseca de comportamento e tomada de decisão da população local, participou com $15,7 \%$ do valor da DAP e 13,6\% do valor da DAR. Os valores das duas componentes não são totalmente levados em consideração nas análises privadas dos ativos naturais, o que, no caso específico da canga, poderia subestimar o valor da DAP pela preservação em $36,2 \%$ e o valor da DAR em 30,4\% pela supressão da vegetação de canga da Flona de Carajás.

Esses resultados apresentam contribuições não reveladas nos trabalhos consultados, dada a interação entre a economia e a ecologia na especificação do modelo, bem como a estimação simultânea dos parâmetros das equações DAP e DAR. Além disso, o adequado desenho do questionário e a ampla informação dada ao entrevistado sobre a canga reduziram a diferença entre os valores da DAP e da DAR, conforme a pressuposição teórica de alguns estudos (HOHN; RANDALL, 1987; PLOTT; ZEILLER, 2005; CARSON; LOUVIERE, 2011; AMI; APRAHAMIAN; CHANEL, 2014).

Na média, o valor da DAR foi de $\mathrm{R} \$ 4.415,56 /$ ha e superior ao valor da DAP ( $\mathrm{R} \$ 4.073,84 / \mathrm{ha}$ ) em $\mathrm{R} \$ 341,71 / \mathrm{ha}$ (8,39\%), o que demonstra a eficácia da pesquisa na busca de superar os diversos problemas teóricos e técnicos apontados na literatura. Assim, o fornecimento de valores reais de terras com diversos usos contribuiu para dirimir vieses do lado econômico, com relação ao efeito substituição entre recursos públicos e privados. Com efeito, a inclusão da variável dummy foi fundamental para captar o efeito riqueza e/ou distribuição de renda.

O fornecimento de informação ao entrevistado sobre a vegetação de canga, destacando suas características e potencialidades, juntamente com a inclusão de 
questões sobre meio ambiente, biodiversidade, espécies raras, endêmicas, e a aptidão econômica e ecológica da vegetação de canga contribuíram para que a decisão quanto ao valor declarado da DAP ou da DAR ser aderente à realidade do mercado. Além disso, a captação desses efeitos por meio de indicadores e a estimação dos parâmetros das equações de DAP e DAR de forma simultânea foram essenciais para solucionar problemas de multicolinearidade e gerar estimativas não enviesadas e eficientes dos parâmetros do modelo econométrico.

Na Figura 1, os resultados para a DAP e a DAR praticamente coincidiram nas vilas Onalício Barros e Planalto. Por outro lado, a diferença foi mais elevada nas vilas da Área de Proteção Ambiental (APA) do Gelado e do Garimpo das Pedras, em que há expectativas de que os direitos de propriedade da terra sejam viabilizados para as comunidades locais, em função de oportunidades econômicas de exploração da área para fins imobiliários (na primeira) e de exploração de jazidas de pedras preciosas e fontes de águas termais (na segunda).

Figura 1 - Valores médios da DAP $(R \$ / h a)$ e da DAR $(R \$ / h a)$ para cada vila, estado do Pará

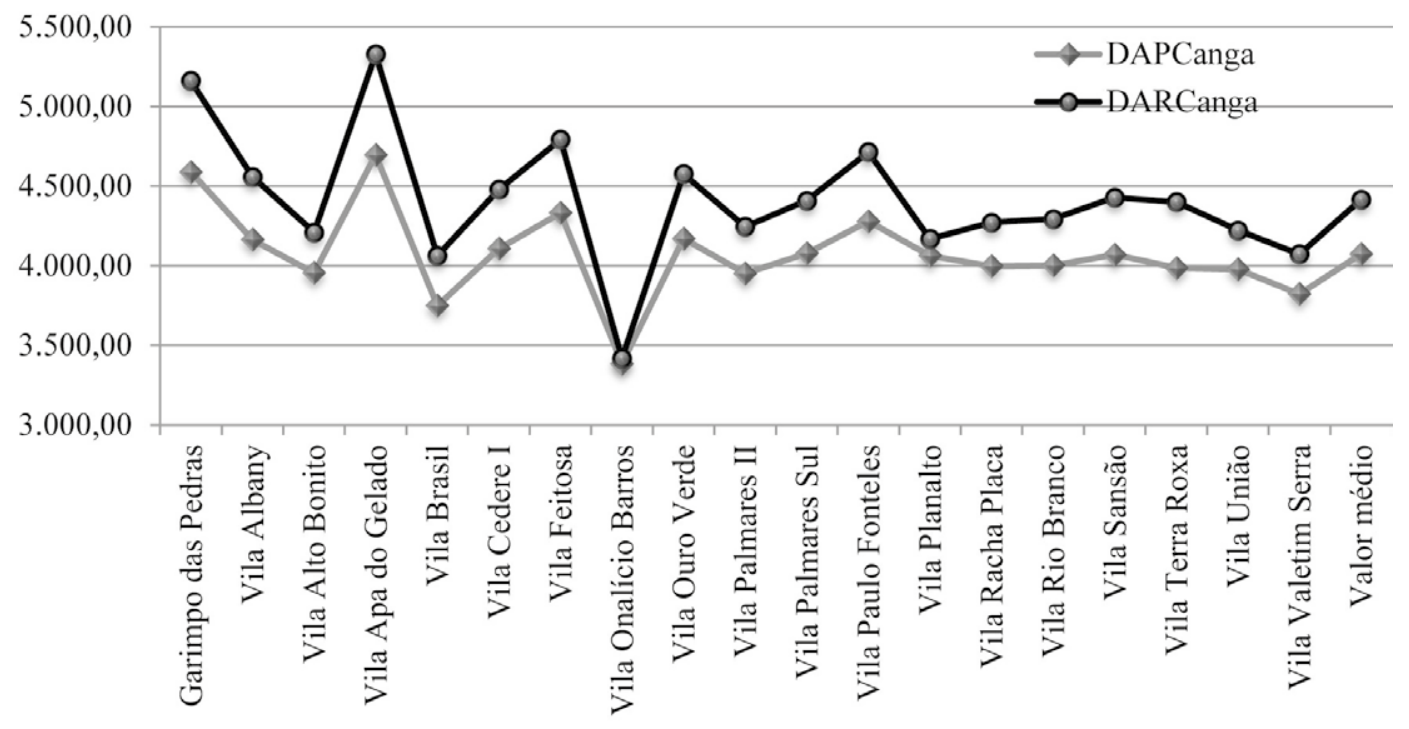

Fonte: dados da pesquisa.

Em geral, os resultados da DAP e DAR foram consistentes para todas as vilas pesquisadas. Portanto, eles corroboraram com os estudos que atribuem a diferença entre os valores da DAP e da DAR aos problemas operacionais e à capacidade e ao conhecimento dos pesquisadores na condução da pesquisa de campo, com vistas a 
reduzir os vieses relacionados à informação, à estratégia dos entrevistados, ao ponto de partida da escala de valor atribuído ao ativo natural e às hipóteses parciais na construção do mercado para o ativo a ser valorado, e não a questões relativas à adequação da pesquisa aos postulados da teoria neoclássica.

\section{Conclusões}

A inclusão das dimensões ambiental, ecológica, econômica, sociodemográfica e tácita para definir as equações de DAP e de DAR, juntamente com a estimação simultânea dos parâmetros por mínimos quadrados generalizados, além de superar os vieses econométricos e metodológicos, tornou o MIAC estatisticamente adequado para estimar o valor econômico total da vegetação de canga da Flona de Carajás.

O conhecimento de $76,92 \%$ dos entrevistados sobre a savana metalófita, juntamente com o esclarecimento sobre o escopo da pesquisa, por meio de fotos e informações de preço das terras de matas e ocupadas com lavouras e pastagens, tornaram as preferências declaradas sobre a DAP e a DAR pela vegetação de canga da Flona de Carajás aderentes à realidade do mercado de terras do bioma Amazônia da área de Carajás.

A contribuição das variáveis incluídas nas dimensões ambiental e ecológica para os valores da DAP e da DAR foi de, respectivamente, 20,5\% e 16,8\%. Esta participação supera o efeito da componente sociodemográfica. Assim, a não inclusão dos efeitos ambientais e ecológicos na avaliação dos ativos ambientais torna o valor econômico total significativamente subestimado e não consistente com a realidade.

O valor médio da DAP pela preservação do ativo ambiental da canga foi estimado em $R \$ 4.073,84 /$ ha, que representa um valor econômico total de $R \$ 83.910 .805,60$, considerando a área total da canga de $20.597,45$ ha. Com efeito, o valor monetário médio da DAR, uma indenização pela supressão da vegetação de canga, foi de $\mathrm{R} \$ 4.415,56 / \mathrm{ha}$, gerando o valor total da indenização de $\mathrm{R} \$ 90.949 .210,74$.

Por fim, conclui-se que a especificação inovadora do modelo e a condução eficiente da pesquisa de campo tornaram a diferença entre os valores da DAP e da DAR de apenas $8,39 \%$. 


\title{
The economic value of the savanna metalófita of the Carajás National Forest, Pará state: a theoretical and methodological contribution
}

\begin{abstract}
The objective of this paper was to estimate the economic value of the canga vegetation in the Carajás Flona, which includes rare and endemic species. An economic and ecological approach was used to choose the explanatory variables of the integrated contingent valuation method (ICVM), specified by the equations willingness to pay (WTP); by the preservation, and the willingness to accept (WTA) by the canga's indemnity. The mean values of WTP and WTA were R $\$ 4,073.84 /$ ha and $\mathrm{R} \$ 4,415.56 /$ ha, respectively. The difference between these average values was only $8.39 \%$, according to the clarifications made to the interviewees regarding the characteristics and economic and ecological potentialities of canga. The values of WTP and WTA were compose by the economic dimensions of $52.1 \%$ and $59.5 \%$; sociodemographic of $11.7 \%$ and $10.2 \%$; ecosystem services of $20.05 \%$ and $16.8 \%$; and tacit dimension of $15.7 \%$ and $13.6 \%$.
\end{abstract}

Keywords: Amazon. Ecosystemic services. Natural capital. Natural resources.

\section{El valor económico de la sabana metalófita del Bosque Nacional de Carajás, estado de Pará: una contribución teórica y metodológica}

\section{Resumen}

El objetivo de este trabajo fue estimar el valor económico de la canga del Bosque Nacional de Carajás, que incluye especies raras y endémicas. Se utilizó un enfoque económico y ecológico en la elección de las variables explicativas del modelo integrado de valoración contingente (MIVC), especificados por las ecuaciones de la disposicióm a pagar (DAP) por la preservación y disposición por cobrar (DAR) para la compensación de la canga. Los valores promedio de la PAD y DAR fueron, respectivamente, $R \$ 4,073.84 /$ ha y $R \$ 4,415.56 /$ ha. La diferencia entre estos valores medios fue sólo $8.39 \%$, de acuerdo con la aclaración hecha a los entrevistados sobre las características y el potencial económico y ecológico de canga. Los valores de PAD y DAR fueron compuestos por las dimensiones económicas de $52.1 \%$ y $59.5 \%$, sociodemográficas de $11.7 \%$ y $10.2 \%$, servicios de los ecosistemas $20.05 \%$ y el $16.8 \%$ y la dimensión tácita $15.7 \%$ y $13.6 \%$.

Palabras clave: Amazonía. Capital natural. Recursos naturales. Servicios de los ecossistemas. 


\section{Referências}

ABDULLAH, S.; JEANTY, S. P. Willingness to pay for renewable energy: evidence from a contingent valuation survey in Kenya. Renewable and Sustainable Energy Reviews, Colorado, v. 15, p. 2974-2983, 2011.

ADAMS, C. et al. The use of contingent valuation for evaluating protected areas in the developing world: economic valuation of Morro do Diabo State Park, Atlantic Rainforest, São Paulo State (Brazil). Ecological Economics, New Hampshire, v. 66, n. 2, p. 359-370, 2008.

AMI, D.; APRAHAMIAN, F.; CHANEL, O. Willingness to pay of committed citizens: a field experiment. Ecological Economics, New Hampshire, v. 105, n. 1, p. 31-39, 2014.

AMIRNEJAD, $\mathrm{H}$. et al. Estimating the existence value of north forests of Iran by using a contingent valuation method. Ecological Economics, New Hampshire, v. 58, n. 3, p. 665-675, 2006.

ARROW, K. J.; FISHER, A. C. Environmental preservation, uncertainty, and irreversibility. Quarterly Journal of Economics, v. 88, n. 2, p. 312-319, 1974.

ARROW, K. J. et al. Report of the National Oceanic and Atmospheric Administration (NOAA). Panel on contingent valuation. Federal Register, Washington, v. 58, n. 10, p. 4602-4614, 1993.

BARAL, N.; STERN, M. J.; BHATTARAI, R. Contingent valuation of ecotourism in Annapurna conservation area, Nepal: implications for sustainable park finance and local development. Ecological Economics, New Hampshire, v. 66, n. 2, p. 218-227, 2008.

BENTES, E. S. et al. Valoração econômica da jusante da barragem de Tucuruí. Revista de Politica Agrícola, Brasília, v. 23, n. 2, p. 102-110, 2014.

BISHOP, R. C.; ROMANO, D. (Ed.). Environmental resource valuation: applications of the contingent valuation method in Italy. Boston: Kluwer Academic Publisher, 1998.

BISHOP, R. C. Option value: an exposition and extension. Land Economics, Madison, v. 58, n. 1, p. l-15, 1982.

CAMPOS, J. C.; CASTILHO, A. F. Uma visão geográfica da região da Flona de Carajás. In: MARTINS, F. D. et al. (Org.). Fauna da Floresta Nacional de Carajás: estudos sobre vertebrados terrestres. São Paulo: Nitro Images, 2012. p. 16-63.

CARSON, R. T. Contingent valuation: a practical alternative when prices aren't available. Journal of Economic Perspectives, Massachusetts, v. 26, n. 4, p. 27-42, 2012.

CARSON, R. T.; CZAJKOWSKI, M. The discrete choice experiment approach to environmental contingent valuation. 2014. Disponível em: <http://econweb.ucsd.edu/ rcarson/>. Acesso em: 3 maio 2014.

CARSON, R. T. et al. Referendum design and contingent valuation: the NOAA panel's no-vote recommendation. Review of Economics and Statistics, Massachusetts, v. 80, n. 2, p. 484-487, 1998.

CARSON, R. T.; LOUVIERE, J. A common nomenclature for stated preference elicitation approaches. Environmental and Resource Economics, Washington, v. 49, n. 4, p. 539-559, 2011.

CARSON, R. T.; MITCHELL, R. C. The value of clean water: the public's willingness to pay for boatable, fishable, and swimmable quality water. Water Resources Research, Washington, v. 29, p. 2445-2454, 1993.

Teoria e Evidência Econômica - Ano 23, n. 48, p. 9-38, jan./jun. 2017 
COSTANZA, R.; DALY, H. E. Natural Capital and Sustainable Development. Conservation Biology, Washington, v. 6, n. 1, p. 37-46, 1992.

COSTANZA, R. et al. The value of the world's ecosystem services and natural capital. Nature, Reino Unido, v. 15, n. 2, p. 253-260, 1997.

CARSON, R. T. et al. Changes in the global value of ecosystem services. Global Environmental Change, Amsterdã, v. 26, n. 1, p. 152-158, 2014.

EVIEWS7. User Guide II. Irvine: QMS, 2012.

FARBER, S. C.; COSTANZA, R.; WILSON, M. A. Economic and ecological concepts for valuing ecosystem services. Ecological Economics, New Hampshire, v. 41, n. 2, p. 375-392, 2002.

FISHER, A. C.; HANEMANN, M. W. Quasi-option value: some misconceptions dispelled. Journal of Environmental Improvement, Haverlee, v. 14, n. 2, p. 183-190, 1987.

FISHER, A. C.; KRUTILLA, J. V.; CICCHETH, C. J. The economics of environmental preservation: a theoretical and empirical analysis. The American Economic Review, Massachusetts, v. 42, n. 4, p. 605-619, 1972.

GREENE, W. H. Econometric analysis. New Jersey: Prentice Hall, 2011.

GROOT, R. et al. Global estimates of the value of ecosystems and their services in monetary units. Ecosystem Services, Netherlands, v. 1, n. 1, p. 50-61, 2012.

HANEMANN, W. M. Valuing the environment through contingent valuation. Journal of Economic Perspectives, Massachusetts, v. 8, n. 1, p. 19-43, 1994.

Willingness to pay and willingness to accept: how much can they differ? The American Economic Review, Massachusetts, v. 81, n. 3, p. 635-647, 1991.

HAUSMAN, J. A. Contingent valuation: from dubious to hopeless. Journal of Economic Perspectives, Massachusetts, v. 26, n. 4, p. 43-56, 2012.

HOEHN, J. P.; RANDALL, A. A satisfactory benefit cost indicator from contingent valuation. Journal of Environmental Economics and Management, Florida, v. 14, n. 2, p. 222-247, 1987.

Too many proposals pass the benefit-cost test. The American Economic Review, Massachusetts, v. 79, n. 3, p. 544-551, 1989.

HOROWITZ, J. K.; MCCONNELL, K. E. A review of WTA / WTP studies. Journal of Environmental Economics and Management, Kiel Germany, v. 44, n. 2, p. 426-447, 2002.

IFNP. Anuário da Agricultura Brasileira. FNP: São Paulo, 2014.

ISONI, A. The willingness-to-accept/willingness-to-pay disparity in repeated markets: loss aversion or "bad-deal" aversion? Theory and Decision, Paris, v. 71, n. 3, p. 409-430, 2011.

IVES, C. D.; KENDAL, D. The role of social values in the management of ecological systems. Journal of Environmental Management, Florida, v. 144, n. 1, p. 67-72, 2014.

KHAN, N. I.; BROUWER, R.; YANG, H. Household's willingness to pay for arsenic safe drinking water in Bangladesh. Journal of Environmental Management, Florida, v. 143, n. 1, p. 151-161, 2014.

KMENTA, J. Elementos de econometria. São Paulo: Atlas, 1978.

KRUTILLA, J. V. Conservation reconsidered. The American Economic Review, Massachusetts, v. 57, n. 4, p. 777-786, 1967.

Teoria e Evidência Econômica - Ano 23, n. 48, p. 9-38, jan./jun. 2017 
LERA-LÓPEZ, F.; FAULIN, J.; SÁNCHEZ, M. Determinants of the willingness-to-pay for reducing the environmental impacts of road transportation. Transportation Research Part D, New York, v. 17, n. 2, p. 215-220, 2012.

LIU, S. et al. Valuing ecosystem services: theory, practice, and the need for a transdisciplinary synthesis. Ecological Economics Reviews, New York, v. 1185, n. 1, p. 54-78, 2010.

LOOMIS, J. et al. Measuring the total economic value of restoring ecosystem services in an impaired river basin: results from a contingent valuation survey. Ecological Economics, New Hampshire, v. 33, n. 1, p. 103-117, 2000.

LOOMIS, J.; WHITE, D. Economic benefits of rare and endangered species. Ecological Economi$c s$, New Hampshire, v. 18, n. 1, p. 197-206, 1996.

PEARCE, D. W. Environmental sustainability and cost benefit analysis. Environment and planning, Columbia, v. 22, n. 1, p. 97-112, 1990.

PLOTT, C. R.; ZEILER, K. The willingness to pay/willingness to accept gap, the endowment effect, subject misconceptions and experimental procedures for eliciting valuations. The American Economic Review, Massachusettes, v. 95, n. 2, p. 530-545, 2005.

The willingness to pay-willingness to accept gap, the "Endowment Effect", subject misconceptions, and experimental procedures for eliciting valuations: reply. The American Economic Review, Massachusettes, v. 101, n. 5, p. 1012-1028, 2011.

RANDALL, A.; STOLL, J. R. Consumer's surplus in commodity space. The American Economic Review, Massachusettes, v. 70, n. 3, p. 449-455, 1980.

RHEE, H-C. Willingness to pay for avoiding infection of climate change diseases, in particular tsutsugamushi disease. Osong Public Health Res Pespect, Korea, v. 4, n. 1, p. 146-200, 2013.

RICHARDES, L.; LOOMIS, J. The total economic value of threatened endangered and rare species: an updated meta-analysis. Ecological Economics, New Hampshire, v. 68, p. 1535-1548, 2009.

SANTANA, A. C. Recent changes in the relations of Brazilian meat demand system. Revista de Economia e Sociologia Rural, Brasília, v. 37, n. 2, p. 161-184, 1999.

. Valoração de produtos florestais não madeireiros da Amazônia: o caso da castanha-do-brasil. 2015. 103 f. Tese (Professor Titular) - Universidade Federal Rural da Amazônia. Belém, 2015.

SANTANA, A. C. et al. An economic valuation of managed roundwood in the region of marajó, in the state of Pará. International Journal of Development Research, India, v. 6, n. 63, p. 72227227, 2016.

SANTANA, A. C.; SANTOS, M. A. S.; SANTANA, A. L. A dinâmica do mercado de terras nos estados do Maranhão, Pará e Tocantins. In: SANTANA, A. C. Mercado, cadeia produtiva e desenvolvimento rural na Amazônia. Belém: UFRA, 2014. p. 21-39.

SANTANA, A. C. Valoração ambiental da área de savana metalófita, ou canga, da Flona de Carajás para fins de indenização. Belém: UFRA; FUNPEA; VALE, 2014. 90p.

SANTANA, A. C. et al. Valoração dos danos ambientais causados por hidrelétricas para a produção de energia na bacia do Tapajós. Reflexões Econômicas, Ilhéus, v. 1, n. 1, p. 31-48, 2015. 
SEIDL, A. F.; MORAES, A. S. Global valuation of ecosystem services: application to the Pantanal da Nhecolandia, Brazil. Ecological Economics, New Hampshire, v. 33, n. 1, p. 1-6, 2000.

SUTHERLAND, R. J.; WALSH, R. G. Effect of distance on the preservation of water quality. Land Economics, Madison, v. 61, n. 2, p. 281-291, 1985.

SUBADE, R. F.; FRANCISCO, H. A. Do non-users value coral reefs?: economic valuation of conserving Tubbataha Reefs, Philippines. Ecological Economics, New Hampshire, v. 102, n. 1, p. 24-32, 2014.

SUTTON, P. C.; COSTANZA, R. Global estimates of market and non-market values derived from nighttime satellite imagery, land cover, and ecosystem service valuation. Ecological Economics, New Hampshire, v. 41, n. 3, p. 509-527, 2002.

TISDELL, C. Biodiversity conservation, loss of natural capital and interest rates. Ecological Economics, New Hampshire, v. 70, n. 33, p. 2511-2515, 2011.

TORRAS, M. The total economic value of Amazonian deforestation, 1978-1993. Ecological Economics, New Hampshire, v. 33, n. 1, p. 283-297, 2000.

VERONESI, M. et al. Climate change and the willingness to pay to reduce ecological and health risks from wastewater flooding in urban centers and the environment. Ecological Economics, New Hampshire, v. 98, n. 1, p. 1-10, 2014. 